\title{
Topic Name - Nail Lacquers in Nail Diseases
}

\author{
Guide- Miss.P.H.Bhapkar ${ }^{1 *}$, Miss.T.Y.Puttewar ${ }^{1}$, Dr.R.Y.Patil ${ }^{1}$ \\ ${ }^{1,2,3}$ Shankarrao ursal college of Pharmaceutical science and research centre Kharadi, Pune
}

\begin{abstract}
Fungal infections of skin are one of the most common infections in human beings. The areas which are likely to get infected include the scalp, the hands and the feet. Dermatophytes, yeasts and moulds are the three major fungi responsible for skin infections. Earlier oral antifungal agents were used for treatment of fungal infection in finger and toe nails. The disadvantages of oral antifungal agents are toxicity and longer treatment period. Now medicated nail lacquers have been developed for the treatment of fungal infections i.e. onychomycosis, which has less toxicity and shorter treatment period.
\end{abstract}

PURPOSE: To provide the practitioner with current information on the most common nail disorders.

TARGET AUDIENCE: This continuing education activity is intended for physicians and nurses with an interest in wound care and related disorders.

KEYWORDS: Toenail, Fingernail, Ciclopirox, Athlet's foot, Amorolfine

\section{INTRODUCTION.}

Fungal nail infection is a common problem affecting around three in every 100 people in the UK. Around half of all nail problems are due to a fungal infection.Fungal nail infection is about four times more common in toenails than fingernails and can involve all or part of the nail, including the nail plate, nailbed and root of the nail.It usually affects adults, especially men, and becomes more common as you get older.Fingernails and toenails are important organs of our body, serving as protection for the tips of fingers and toes. Fingernails also enhance fine touching and tactile sensitivity, as well as aid in the picking up of small objects. Healthylooking nails are an important part of an individual's body image, and any nail abnormalities may be considered by patients as a significant cosmetic problem, markedly influencing their self esteem. However, recent data have indicated that nail lesions are not only important because of cosmetic disfigurement, but may be a symptom of significant morbidity. Severe nail involvement was also shown to negatively impair social functioning and to interfere with work ability, thus markedly influencing a patient's well-being. Based on literature data and our own experience we conclude that nail diseases cause a marked decrease in health-related quality of life in a substantial percentage of patients. Nail changes are an important medical concern for patients and, therefore, nail diseases should raise attention and receive proper care from both physicians and other healthcare providers.

\section{Objectives}

- External application leads lesser side effects.

- Useful for beautification and as well as treatment.

- Formulation well be patient friendly.

- Simpler techniques are required for formulation.

- People will not fill it as medication.

- This formulation change the view of medication.

\section{Nail Anatomy \& Structure.}

A nail is a horn-like envelope covering the dorsal aspect of the terminal phalanges of fingers and toes in humans, most non-human primates, and a few other mammals. Nails are similar to claws, which are found on numerous other animals. Fingernails and toenails are made of a tough protein called keratin, as are animals' hooves and horns. The nail consists of the nail plate, the nail matrix and the nail bed below it, and the grooves surrounding it. 


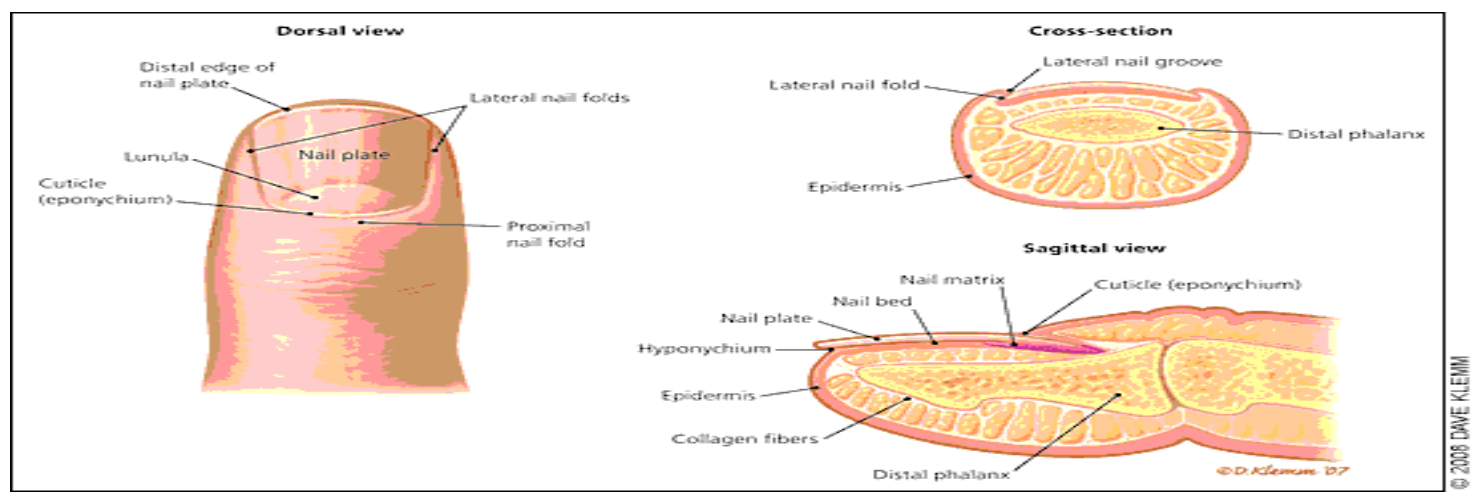

Fig1: nail anatomy structure

Nail Structure: The nail is a complex unit composed of five major modified cutaneous structures: the nail matrix, nail plate, nail bed, cuticle (eponychium), and nail folds1 (Figure 1). The cuticle is an outgrowth of the proximal fold and is situated between the skin of the digit and the nail plate, fusing these structures together. 2 This configuration provides a waterproof seal from external irritants, allergens, and pathogens.

Nail bed :Injury to the germinal matrix may lead to permanent nail loss.

Nail plate : The nail plate is the hard and translucent portion of the nail, composed of keratin. The fingernail itself, the thing that you cut with a fingernail clipper, is called the nail plate.

Nail Root : The root of the fingernail is also known as the germinal matrix. This portion of the nail is actually beneath the skin behind the fingernail and extends several millimeters into the finger. The fingernail root produces most of the volume of the nail and the nail bed. This portion of the nail does not have any melanocytes, or melanin producing cells. The edge of the germinal matrix is seen as a white, crescent shaped structure called the lunula.

Cuticle: The cuticle of the fingernail is also called the eponychium. The cuticle is situated between the skin of the finger and the nail plate fusing these structures together and providing a waterproof barrier.

Perionychium:The perioncyhium is the skin that overlies the nail plate on its sides. It is also known as the paronychial edge. The perionychium is the site of hangnails, ingrown nails, and an infection of the skin called paronychia.

Hyponychium :The hyponychium is the area between the nail plate and the fingertip. It is the junction between the free edge of the nail and the skin of the fingertip, also providing a waterproof barrier

Growth :The growing part of the nail is under the skin at the nail's proximal end under the epidermis, which is the only living part of a nail.In mammals, the length and growth rate of nails is related to the length of the terminal phalanges (outermost finger bones). Thus, in humans, the nail of the index finger grows faster than that of the little finger; and fingernails grow up to four times faster than toenails.In humans, nails grow at an average rate of $3 \mathrm{~mm}(0.12 \mathrm{in})$ a month (as they are a form of hair).Fingernails require three to six months to regrow completely, and toenails require 12 to 18 months. Actual growth rate is dependent upon age, sex, season, exercise level, diet, andhereditary factors. Nails grow faster in the summer than in any other season.

Contrary to popular belief, nails do not continue to grow after death; the skin dehydrates and tightens, making the nails appear to grow.

\section{Function of nail.}

- $\quad$ Fingernails actually help protect your fingers. If they weren't there the tips of your fingers would get all scratched up. It also seems like they help us the grab hold of things.

- A healthy finger nail has the function of protecting the distal phalanx, the fingertip, and the surrounding soft tissues from injuries. It also serves to enhance precise delicate movements of the distal digits through counter-pressure exerted on the pulp of the finger.

- The nail then acts as a counterforce when the end of the finger touches an object, thereby enhancing the sensitivity of the fingertip 
- $\quad$ even though there are no nerve endings in the nail itself. Finally, the nail functions as a tool, enabling for instance a so-called "extended precision grip" (e.g. pulling out a splinter in one's finger).

\section{NAIL HEALTH AND ABNORMALITIES}

The nails are present at the end of each finger tip on the dorsal surface.The main function of nail is protection and it also helps for a firm grip for holding articles.It consists of a strong relatively flexible keratinous nail plate originating from the nail matrix. Under the nail plate there is a soft tissue called nail bed.Between the skin and nail plate there is a nail fold or cuticle.Normal healthy nail is slight pink in colour and the surface is convex from side to side.Finger nails grow $1 \mathrm{~cm}$ in three months and toe nails take 24 months for the same.

Importance of nails in disease diagnosis: The colour, appearance,shape and nature of the nails give some information about the general health and hygiene of a person. Nails are examined as a routine by all doctors to get some clues about underlying diseases.Just looking at nails we can makeout the hygiene of a person.The abnormal nail may be congenital or due to some diseases.The cause for changes in the nail extend from simple reasons to life threatening diseases.Hence the examination by a doctor is essential for diagnosis .Some abnormal findings with probable causes are discussed here for general awareness.

1) Hygiene:- We can make out an unhygienic nail very easily .Deposition of dirt under the distal end of nail plate can make a chance for ingestion of pathogens while eating.If nail cutting is not done properly it can result in worm troubles in children. When the worms crawl in the anal orifice children will scratch which lodges the ova of worms under the nails and will be taken in while eating.Prominent nail can also complicate a skin disease by habitual scratching.Sharp nails in small kids cause small wounds when they do feet kicking or hand waving.

2) Colour of the nails:-

a) Nails become pale in anaemia.

b) Opaque white discolouration(leuconychia) is seen in chronic renal failure and nephrotic syndrome.

c)Whitening is also seen in hypoalbuminaemia as in cirrhosis and kidney disorders.

d) Drugs like sulpha group,anti malarial and antibiotics ect can produce discolouration in the nails.

e) Fungal infection causes black discolouration.

f) In pseudomonas infection nails become black or green.

g) Nail bed infarction occures in vasculitis especially in SLE and polyarteritis.

h) Red dots are seen in nails due to splinter haemorrhages in subacute bacterial endocarditis, rheumatoid arthritis, trauma, collagen vascular diseases.

i) Blunt injury produces haemorrhage and causes blue/black discolouration.

j) Nails become brown in kidney diseases and in decreased adrenal activity.

k) In wilsons disease blue colour in semicircle appears in the nail.

1) When the blood supply decreases nail become yellow.In jaundice and psoriasis also nail become yellowish.

m) In yellow nail syndrome all nails become yellowish with pleural effusion.

\section{Tips for keeping nails healthy}

[1] Keep your nails clean and dry to prevent bacteria from collecting under the nail.

[2] Cut your fingernails and toenails straight across and rounded slightly in the center. This keeps your nails strong and helps avoid ingrown toenails.

[3] When toenails are thick and difficult to cut, soak feet in warm salt water (one teaspoon of salt per pint of water) for five to 10 minutes, then apply urea or lactic acid cream. This softens the nails, making them easier to trim.

[4] Wear proper-fitting shoes and alternate shoes on a regular basis. Tight shoes can cause ingrown toenails.

[5] Do not try to self-treat ingrown toenails, especially if they are infected. See a dermatologist.

[6] Do not bite your fingernails. You can transfer infectious organisms between your fingers and mouth. Also, nail biting can damage the skin around your fingers, allowing infections to enter.

[7] Nail problem are more common if you have diabetes or poor circulation. At the first sight of a problem, see a dermatologist. ${ }^{[23]}$

\section{Nail Abnormalities}

Lifting of the nail plate : A normal nail is translucent and its pink colour is provided by the nail bed. The end of the nail appears white because of the air beneath it and if the nail becomes separated from the bed the white colour will extend down the nail. This condition is often a result of repeated minor injury to the underside of the nail, (for example, excessive cleaning under the free edge of the nail). 


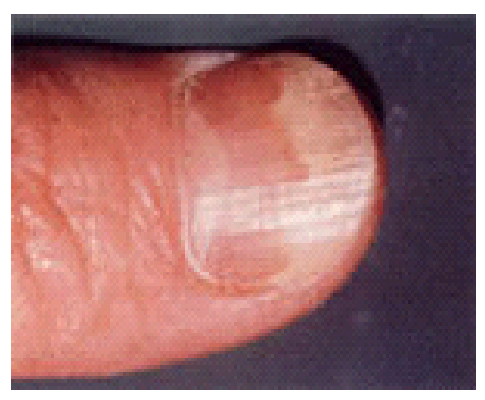

fig2:Lifting of the nail plate

\section{RIDGING OF THE NAIL}

Ridging in nails can be either along (longitudinal) or across (transverse) the nail. Longitudinal ridging normally becomes more prominent with age, but can also be associated with medical conditions such as rheumatoid arthritis, lichen planus and injury to the nail. Transverse depressions often appear some weeks after an illness or fever and grow out with the nail. Alternatively they may be caused by longstanding or severe eczema around the nail fold and also trauma from pushing back the cuticle. Transverse layering or nail splitting This is a frequent abnormality which involves splitting of the free end of the nail into layers. It is commonly seen in people who frequently immerse their hands in water as part of their work or home duties.

Thickening of the nail : Thickening of the nail can occur as a result of dermatological or general medical disease, and is most frequently seen in the toenails of the elderly. It often results from the long term use of illfitting footwear and neglect of the nails. When psoriasis and other skin conditions affect the nail, they often lead to thickening of the nail. If a fungal infection is suspected to have caused the nail thickening a sample of the thickened nail can be collected and analysed by a laboratory. If this confirms a fungal infection specific treatments are available.

Discolouration : Medications, chemicals from hair dyes and nail varnish, nicotine and creams such as Dithranol can all cause discolouration of the nail. Antibiotics can cause nail lifting an brownish discolouration of the nail plate. Antimalarial medications and agents used in chemotherapy may also cause discolouration. Bleeding beneath the nail plate can also cause dark discolouration. Melanoma is another important cause of nail discolouration and may involve the nail bed, nail and/or cuticle. You should see your doctor is new or changing pigmentation of the nail or around the nail occurs.

Inflammation of the nail fold. : Bacterial infection of the nail fold causes redness, swelling, tenderness and pain usually around the proximal nail fold, sometimes with pus formation. The most common cause is bacterial infection with Staphyloccusaureus. This condition is often seen in nurses, hospitality workers and anyone involved in activities where nails are immersed in water for periods of time. Damage to the cuticle, through immersion in water or over-zealous manicuring, also predisposes to this form of inflammation.

Nail disease of traumatic origin : Nail biting is associated with infection around the nail folds and can cause deformity of the nail plate. Constant fiddling with the nails can produce longitudinal depressions along the nail. Nail cosmetics, particularly nail hardeners containing formalin, can cause separation of the nail plate from the nail bed. Adhesives used to attach artificial nails can be associated with nail and skin inflammation. ${ }^{[18]}$

4.Introdution of Fungal Infection : Fungal infections, such as tinea, are spread from one person to another and can involve the fingernails or toenails. People with diabetes or with compromised immune systems are at increased risk of fungal infection. The characteristics of a fungal nail infection depend on the infectious agent, but may include:

- $\quad$ Lifting of the nail plate off the nail bed

- Thickening of the nail plate

- Crumbling of the nail plate

- Discolouration, usually in streaks

- Flaking and pitting of the nail plate surface 
Fungal Nail Infections : Fungal infection of nails is common. The infection causes thickened and unsightly nails which sometimes become painful. Medication often works well to clear the infection, but you need to take medication for several weeks.

\section{Who gets fungal nail infections?}

Between 3 and 8 out of 100 people in the UK will have a fungal nail infection at some stage of their lives. Toenails are more commonly affected than fingernails. It is more common in people aged over 55, and in younger people who share communal showers, such as swimmers or athletes.

\section{How do you get a fungal nail infection?}

- Spread from a fungal skin infection. For example, athlete's foot is a fungal skin infection of the toes. This may spread to the toenails if the skin infection is not treated early.

- $\quad$ Fingernail infection may occur after a toenail infection has become established. The fungus may spread to a finger if you scratch your itchy toes and toenail.

- Fingernail infections are also more likely to occur if you wash your hands frequently, or have them in water a lot. For example, if you are a cook or a cleaner. Constant washing may damage the protective skin at the base of the nail. This may allow fungi to enter.

- A nail that has recently been damaged is also more likely to become infected.

- You have an increased risk of developing a fungal nail infection if you have various other conditions. For example: diabetes, psoriasis, poor circulation, a poor immune system (for example, if you have AIDS or are on chemotherapy), or a general poor state of health.

- Nail infections are more common in people who live in hot or humid climates.

- Smoking also increases the risk of developing a nail infection.

- In some cases there is no apparent reason. Fungus germs (fungi) are common and an infection can occur 'out of the blue'.

\section{What are the symptoms of a fungal nail infection?}

Often the infection is just in one nail, but several may be affected. At first the infection is usually painless. The nail may look thickened and discoloured (often a greeny-yellow colour). Commonly, this is all that occurs and it often causes no other symptoms. However, it can look unsightly. Sometimes the infection becomes worse. White or yellow patches may appear where the nail has come away from the skin under the nail (the nailbed). Sometimes the whole nail comes away. The nail may become soft and crumble. Bits of nail may fall off. The skin next to the nail may be inflamed or scaly. If left untreated, the infection may eventually destroy the nail and the nailbed, and may become painful. Walking may become uncomfortable if a toenail is affected.

\section{What is the treatment for a fungal nail infection? \\ Not treating}

This is an option if the infection is mild or causing no symptoms. For example, a single small toenail may be infected and remain painless and of little concern. Some people may prefer not to take treatment because:

- Treatment does not always cure the infection. Cure rates are about $60-80 \%$.

- Treatment that clears the infection does not always restore the nail's appearance to normal.

- The antifungal medicines used for treatment need to be taken for several months - sometimes longer.

- $\quad$ Although rare, unpleasant side-effects sometimes occur with antifungal medicines.

The option to treat can be reviewed at a later date if the infection becomes worse or if you change your mind.

However, treatment is usually advised if:

- $\quad$ Symptoms are troublesome. For example, if walking is uncomfortable due to an affected nail.

- Abnormal-looking nails cause distress.

- You have diabetes, vascular disease or a connective tissue disorder (because of a higher risk for secondary bacterial infections and cellulitis).

- The nail infection is thought to be the source of a fungal skin infection on your body.

- You have, or are likely to develop, severe problems with your immune system. For example, if you are to have certain types of cancer treatment. 
Medication : Antifungal tablets will often clear a fungal nail infection. The medication will also clear any associated fungal skin infection, such as athlete's foot. Your doctor will usually recommend one of the following two medicines. The one chosen may depend on the type of fungus causing the infection. Both of these medicines cause side-effects in a small number of people, so read the packet that comes with the medicine for a full list of cautions and possible side-effects.

- Terbinafine tablets. The usual adult dose is $250 \mathrm{mg}$ once a day; for between 6 weeks and 3 months for fingernails, and for 3-6 months for toenails. Visible improvement can be expected after the end of two months of treatment for fingernails and three months of treatment for toenails.

- Itraconazole tablets. This is usually given as pulsed treatment. That is, for an adult: $200 \mathrm{mg}$ twice a day for one week, with subsequent courses repeated after a further 21 days. Fingernail infections require two pulsed courses and toenail infections require at least three pulsed courses. Studies suggest that in about 5 in 10 cases the nail will look fully normal again after treatment. In about a further 2 in 10 cases the fungus will be cleared from the nail after treatment, but the nail does not look fully normal again. Fingernails tend to respond better to treatment than toenails do. One reason for treatment to fail is because some people stop their medication too early.

Antifungal nail paint (nail lacquer) : A nail lacquer that contains the antifungal medicine amorolfine is an alternative for most (but not all) types of fungi that infect nails. You can buy amorolfine nail lacquer from pharmacies as well as getting it on prescription. However, this tends not to work as well as medication taken by mouth. Your doctor will advise if it is a suitable option for your type of infection. For example, it may be useful if the infection is just towards the end of the nail. This treatment does not tend to work so well if the infection is near the skin, or involves the skin around the nail. The nail lacquer has to be put on exactly as prescribed for the best chance of success. You may need six months of nail lacquer treatment for fingernails, and up to a year for toenails. Tioconazole is another solution that can be applied to the nail. It can also be bought from a pharmacy, although research trials suggest it does not work as well as amorolfine.

Nail removal : If other treatments have failed, an option is to have the nail removed by a small operation done under local anaesthetic. This is combined with treatment with antifungalmedication.

\section{What to look out for with treatment?}

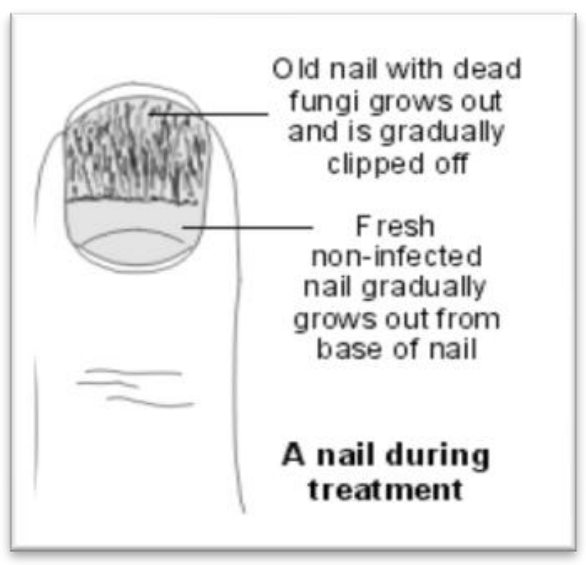

fig3: nail treatment.

The fungi that are killed with treatment remain in the nail until the nail grows out. Fresh, healthy nail growing from the base of the nail is a sign that treatment is working. After you finish a course of treatment, it will take several months for the old infected part of the nail to grow out and be clipped off. The non-infected fresh new nail continues growing forward. When it reaches the end of the finger or toe, the nail will often look normal again.Fingernails grow faster than toenails, so it may appear they are quicker to get back to normal. It may take up to a year after starting treatment before toenails look completely normal again and six months for fingernails to look completely normal.Consult a doctor if there does not seem to be any healthy new nail beginning to grow after a few weeks of treatment. However, the infection can still respond to treatment even after you finish a course of medication. This is because the antifungal medication stays in the nail for about nine months after you stop taking medication. 


\section{What can I do to help?}

Take medication as directed, and do not give up without discussing this with a doctor.

Side-effects are uncommon with modern medication, but tell a doctor if you notice any problems with treatment.

Tips on nail care if you have a nail infection, with or without taking medication, include the following.

- Keep your nails cut short, and file down any thickened nail.

- Use a separate pair of scissors to cut the infected nail(s) to prevent contaminating the other nails. Do not share nail scissors with anyone else (for the same reason).

- Avoid injury and irritants to your nails. For example, if fingers are affected, use cotton and vinyl gloves for wet work. Use heavy cotton gloves for dry work.

- If toenails are affected, wear properly fitted shoes with a wide toe box.

- Keep your feet cool and dry as much as possible.

\section{Preventing fungal nail infections}

Studies suggest that in about 1 in 4 cases where the infection has been cleared from the nail, the infection returns within three years. One way to help prevent a further bout of nail infection is to treat athlete's foot as early as possible to stop the infection spreading to the nail. Athlete's foot is common and may recur from time to time. It is easy to treat with an antifungal cream which you can buy from pharmacies, or get on prescription. The first sign of athlete's foot is itchy and scaling skin between the toes. See separate leaflet called Athlete's Foot (TineaPedis) for further detail. Also:

- Try to avoid injury to nails, which may increase the risk of developing a nail infection.

- Wear footwear such as flip-flops in public places, such as communal bathing/shower places, locker rooms, etc.

- Avoid towel sharing.

- Consider replacing old footwear, as this could be contaminated with fungal spores.

\section{FUNGAL NAIL DISEASE.}

\subsection{Onychomycosis}

Onychomycosis (also known as "dermatophytic onychomycosis," or"tinea unguium") means fungal infection of the nail.It is the most common disease of the nails and constitutes about a half of all nail abnormalities. This condition may affect toenails or fingernails, but toenail infections are particularly common. The prevalence of onychomycosis is about $6-8 \%$ in the adult populationOnychomycosis is an infection of the nail caused by fungi such as dermatophytes, non-dermatophytemoulds and yeasts (mainly Candida species). Of these $80 \%$ of the toenail infections are caused by dermatophytes (Trichophytonrubrum). Onychomycosis is classified clinically as distal and lateral subungualonychomycosis (DLSO), superficial white onychomycosis (SWO), proximal subungualonychomycosis (PSO), candidialonychomycosis and total dystrophic onychomycosis.

\section{Distal and lateral subungualonychomycosis:}

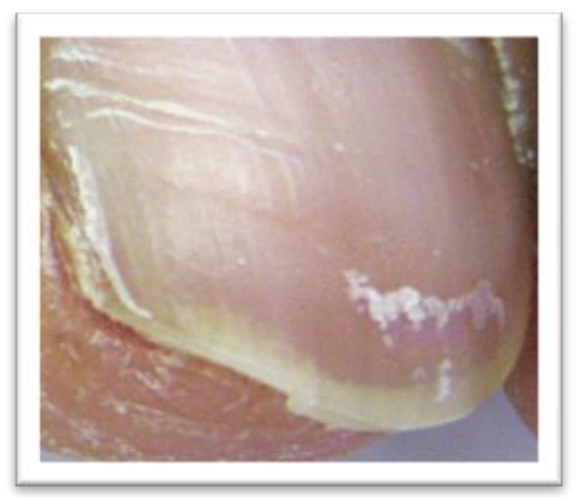

Fig4:Distal\&laststeralsubungualonchomy. 
Distal and lateral subungualonychomycosis are seen in majority of cases and is almost always due to dermatophyte infection. It affects the hyponychium, often at the lateral edges initially, and spreads proximally along the nail bed resulting in subungual hyperkeratosis and onycholysis although the nail plate is not initially affected. Distal and lateral subungualonychomycosis may be confined to one side of the nail or spread sideways to involve the whole of the nail bed, and progresses relentlessly until it reaches the posterior nail fold. Eventually the nail plate becomes friable and may break up, often due to trauma, although nail destruction may be related to invasion of the plate by dermatophytes that have keratolytic properties. Examination of the surrounding skin will nearly always reveal evidence of tineapedis. Toenail infection is an almost inevitable precursor of fingernail dermatophytosis, which has a similar clinical appearance although nail thickening is not as common.

Features of DLSO are as follows:

- Subungual hyperkeratosis and onycholysis, which is usually yellow-white in color

- Yellow streaks and/or yellow onycholytic areas in the central portion of the nail plate

\section{Superficial white onychomycosis:}

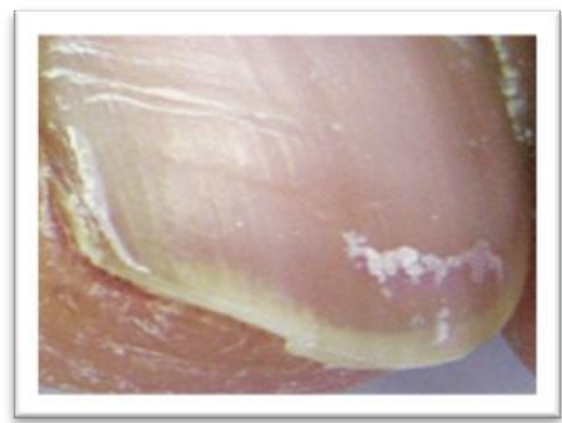

Fig5:Superficial white onychmycosis.

Superficial white onychomycosis is also, also a dermatophyte infection, which is caused by $T$. mentagrophytes. It is much less common than distal and lateral subungualonychomycosis and affects the surface of the nail plate rather than the nail bed. Discoloration is white rather than cream and the surface of the nail plate is noticeably flaky. Onycholysis is not a common feature of superficial white onychomycosis and intercurrent foot infection is not as frequent as in distal and lateral subungualonychomycosis.

Features of WSO are as follows:

- Confined to the toenails

- Small, white, speckled or powdery patches on the surface of the nail plate

- The nail becomes roughened and crumbles easily

- Molds produce a deep variety of WSO characterized by a larger and deeper nail plate invasion

\section{Proximal subungualonychomycosis:}

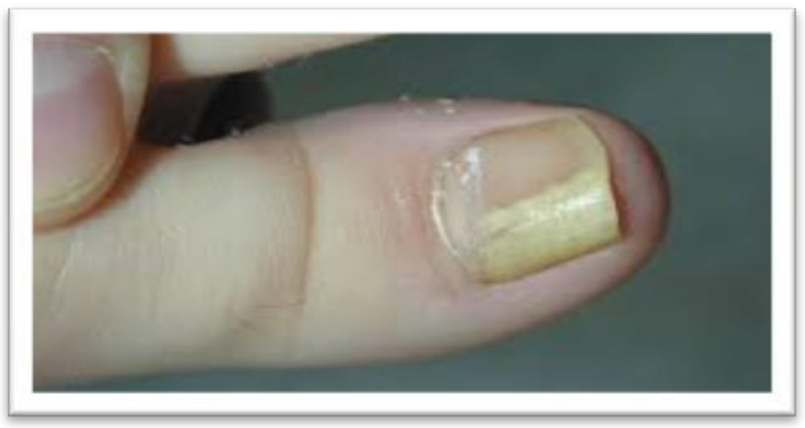

Proximal subungualonychomycosis is an uncommon variety of dermatophyte infection often related to intercurrent disease. Immunosuppressed patients, notably those who are human immunodeficiency viruspositive, may have a variety of dermatophyte infection; conditions such as peripheral vascular disease and 
diabetes also may present in this way. Evidence of intercurrent disease should therefore be considered in a patient with proximal subungualonychomycosis.

Features of PSO are as follows:

- An area of leukonychia in the proximal nail plate that moves distally with nail growth

- In PSO caused by molds, leukonychia is typically associated with marked periungual inflammation

\section{Candidalonychomycosis:}

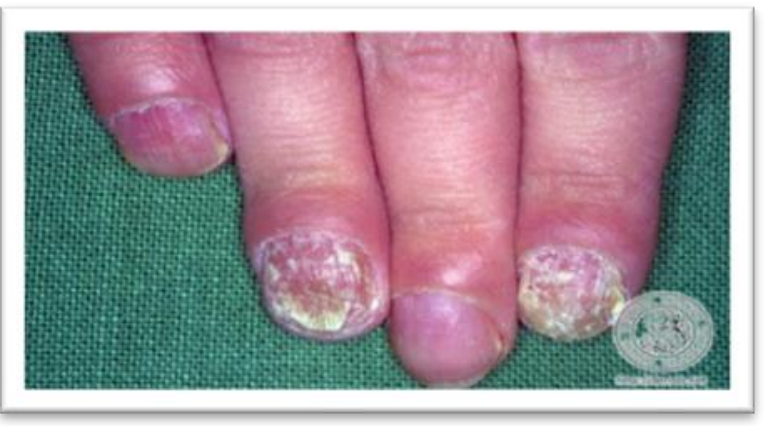

Infection of the nail with Candida yeasts may present in one of the following four ways, (i) chronic paronychia with secondary nail dystrophy; (ii) distal nail infection; (iii) chronic mucocutaneous candidiasis; and (iv) secondary candidiasis.Chronic paronychia of the fingernails generally occurs in patients with wet occupations. Swelling of the posterior nail fold occurs secondary to chronic immersion in water or possibly due to allergic reactions to some foods, and the cuticle becomes detached from the nail plate thus losing its watertight properties. Microorganisms, both yeasts and bacteria, enter the subcuticular space causing further swelling of the posterior nail fold. Distal nail infection with Candida yeasts is uncommon and virtually all patients have Raynaud's phenomenon or some other form of vascular insufficiency.Chronic mucocutaneous candidiasis, involves the mucous membranes which is caused due to diminished cell-mediated immunity. Clinical signs vary with the severity of immunosuppression, but in more severe cases gross thickening of the nails occurs, amounting to a Candida granuloma. Secondary candidalonychomycosis occurs due to other diseases of the nail, mostly psoriasis Onychomycosis is fungal infection of the nail plate, nail bed, or both. The nails typically are deformed and discolored white or yellow. Diagnosis is by appearance, wet mount, culture, PCR, or a combination. Treatment, when indicated, is with selective use of oral terbinafine or itraconazole. About $10 \%$ (range 2 to $14 \%$ ) of the population has onychomycosis.

\section{RISK FACTORS INCLUDE}

- $\quad$ Tineapedis

- $\quad$ Preexisting nail dystrophy (eg, in patients with psoriasis)

- Older age

- Male sex

- Exposure to someone with tineapedisor onychomycosis

- Peripheral vascular disease or diabetes

- Immunocompromise

Toenails are 10 times more commonly infected than fingernails. About 60 to $80 \%$ of cases are caused by dermatophytes (eg, Trichophytonrubrum); dermatophyte infection of the nails is called tineaunguium. Many of the remaining cases are caused by nondermatophyte molds (eg, Aspergillus, Scopulariopsis, Fusarium).Immunocompromised patients and those with chronic mucocutaneous candidiasis may have candidalonychomycosis (which is more common on the fingers). Subclinical onychomycosis can also occur in patients with recurrent tineapedis. Onychomycosis may predispose patients to lower extremity cellulitis.

Features of candidal onychomycosis are as follows:

- Develops in patients with chronic mucocutaneous candidiasis or immunodepression

- Affects several or all digits

- Total onychomycosis associated with periungual inflammation

- The digits often take on a bulbous or drumstick appearance 


\section{TO CRUSH (TREAT) NAIL YEAST INFECTIONS.}

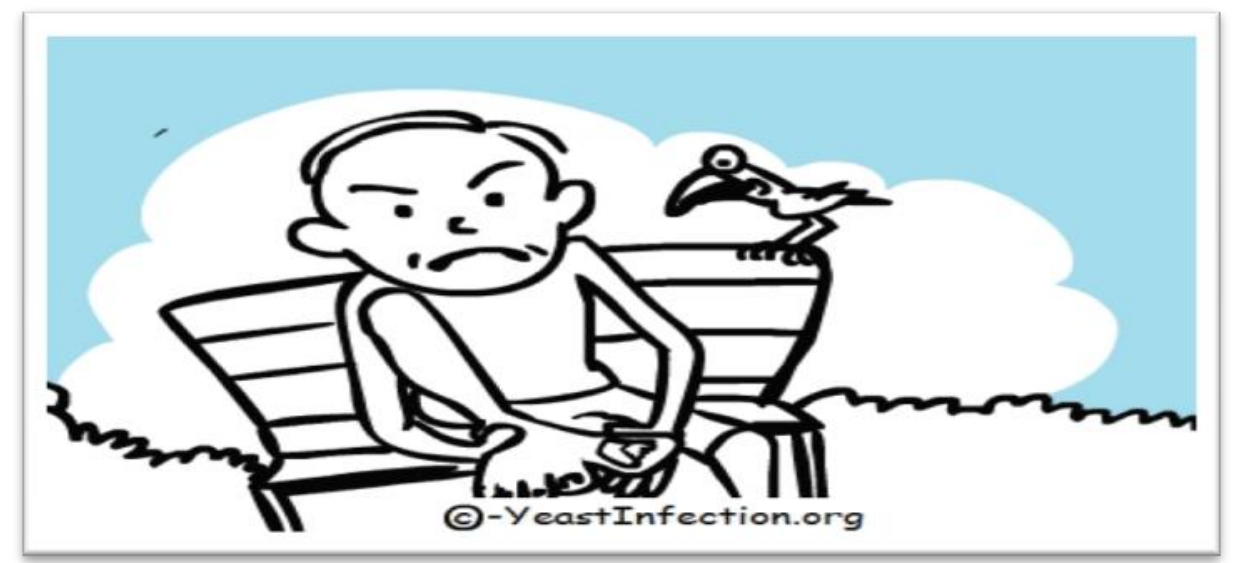

Fig14:Nail Yeast Infection.

Fungal conditions affecting the nails are a problem that affects countless people all over the world. Every month, many people go to Google in an attempt to discover how to eradicate athlete's foot and nail yeast infections.To reduce your chances of developing and maintaining fungal nail infections, I highly recommend that you follow these ten rules. You will notice that quite a few of the lifestyle recommendations are based on the fact that nail yeast infections thrive in an environment which is warm, dark and moist and is fed on sugars and yeast foods in theperson's diet - not unlike a woman's or man's yeast infection. Knowing this, think about keeping the hands and feet clean and dry where possible, and take away the food supply that a nail yeast infection likes to feed on - the sugar and yeast foods.Here are some of the best hints and tips I have learned over the years which will help you crush fungal nail problems permanently.

Keep your hands and feet clean and dry: One of the best ways to avoid yeast infections of the nails is to make certain that your hands and feet are dry and dirt-free most of the time, because fungus loves to exist and grow in dark, moist and warm areas such as sweaty hands (gloves) or sweaty sports shoes. Fingernail yeast infections often begin from hands and fingers in particular being hot and sweaty, cleaned several times daily or submerged for prolonged times in water. A fungal nail problem is more common in those who wear rubber gloves for several hours a day. Toenail fungal problems often begin from too much shoe use, the most common cause. Those who are more prone are office workers and especially those who play sports and end up with hot and sweaty feet. Now you can understand why locker rooms, swimming pool areas and shower rooms are notorious for spreading athlete's foot and toe nail fungus. It is very important that you keep your feet clean and dry, especially between your toes. Some people use a hair-dryer to get their feet completely dry.

2: Go barefoot : Whenever you can, kick-off your shoes and go barefoot. It is a fact that those who wear shoes and socks continuously will have a greater chance of nail fungal problems. Going barefoot on the beach is particularly good, and you will get rid of athlete's foot and nail fungus that much quicker if you visit the beach more often.

3: Sunlight : Place you feet in the sun, because yeast hates bright light. That's right, kick off those shoes and place your feet in the sun when you can for 15 minutes a day. This is why the beach is such a great environment and incorporates all the elements which yeasts hate - sun, clean salty water and fresh air. I have yet to meet a person with fungal toenails or athlete's feet who loves spending time at the beach.

4: Replacing your socks is important : Always use cotton socks, especially if you have an existing fungal nail problem or athlete's foot. Change your socks every day, and after you wash or bathe be sure to dry your feet carefully before you put a fresh new pair of cotton socks on. Add a little tea tree oil powder to your socks and feet, Thursday Plantation has a tea tree oil powder and you will be able to get it at Amazon or elsewhere online.

5: Rotate your footwear and wear sandals in summer: Avoid wearing the same closed footwear day each day, rotate your footwear. Leave the pair you wore yesterday in a place where they can air or dry out. Go and 
buy another two or three pairs of shoes, especially sports shoes. Drop one single drop of tea tree oil into the shoe, where the toes are, at least twice or three times each week. Wear sandals or open footwear, particularly in warmer weather, that way the air and light can more easily come into contact with your toes and feet.

6: Use natural remedies, forget drugs : You don't need to use pharmaceutical preparations like creams, ointments of pills to eradicate a fungal nail or foot condition. Why use something that may give you a serious side-effect? Natural anti-fungal medicines like tea tree oil will naturally prohibit the development of nail fungus and athlete's foot - without the risk of side-effects.

7: Foot spa or foot bath : A foot bath or a foot spa to which you have added a generous amount of ACV is one of the most effective home treatments for nail or athlete's feet fungal problems. Soak your feet in a bowl or foot spa with tepid water to which you have added a half a cup of ACV. Add one teaspoon of colloidal silver in addition and let the feet soak for at least 30 minutes, after which you should dry your feet thoroughly. Remember the hair dryer? Then dust your feet of nails with a little tea tree oil powder.

8: Use tea tree oil.: Australian tea tree oil (Melaleucaalternifolia) in my opinion is the best product to cure any nail yeast infection or athlete's foot. I have seen it cure countless nail and foot problems for many, many years. Drop the pure oil onto your nail or feet twice daily. You must be persistent and keep applying the tea tree oil each morning and each night.

9: Be cautious of artificial nails and nail salons. : Artificial nails and heavily painted nails are potential breeding grounds for fingernail fungal infections. Be careful if you visit a nail salon, if they are not practicing correct sanitizing measures they can spread the fungal infection to other clients. A nail yeast infection may imbed more deeply if an artificial nail is layered onto an infected nail, and this may even be done to cover an unsightly finger nail.

10: Crushed garlic. :Peel a clove of garlic and then crush it until it is a fine pulp. Apply the garlic pulp to the toe or rub it very well into the affected area if a large area is affected. Place a large sticking plaster over the affected toe if you can, with the pulp underneath which is in contact with the fungal toe. Leave it overnight and in the morning wash the area and drop one drop of tea tree oil on the area. Repeat several times a week.

11: NEVER GIVE UP :I always recommend persistence, because a fungal toenail will require persistence on your part if you want to eradicate it. It will not go away after just a few treatments, but will require daily treatment at times for weeks. You will eradicate this problem completely if you follow the 10 points outlined above consistently.

\section{NAIL LACQUER PREPARATION}

A method of making a solvent based ink formulation which includes a thermochromic pigment, wherein the pigment being formed of microcapsules, includes drying a slurry that contains the pigment to a solids concentration between $80 \%$ and $95 \%$, mixing the dried slurry in an appropriate mixing base, and adding any desired ink components to the base formulation. Each microcapsule contains a reversible thermochromic coloring material which exhibits a visible change in color between a first color state and a second color state in response to a change in temperature. Acceptable ink components include a gel vehicle, a free flow vehicle, a drying agent, a lithographic varnish, an ink wax, a polyester vehicle, a polyglycol solvent, a colloidal dispersion resin, water, and defoamer.

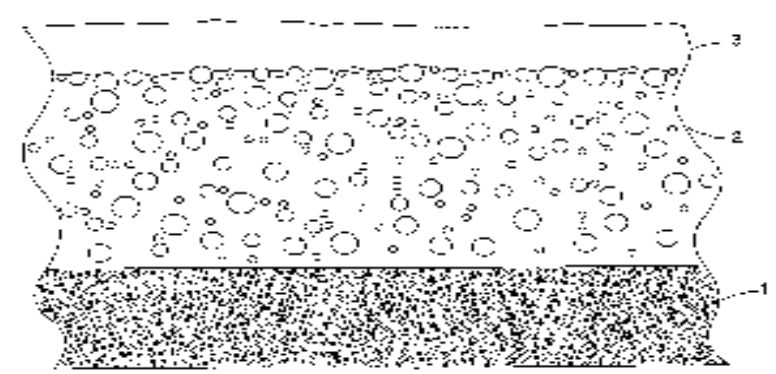

Fig15:Method of ink formulation. 
Required qualities :

- Must have an important adhesive power

- $\quad$ Shining film

- Easy application, easy spreadibility

- Homogeneity

- Fast drying

- High covering power

- Plasticity and flexibility to prevent cracks Hardness.

7.1 Formulation Table

\begin{tabular}{|c|c|c|c|c|c|}
\hline \multicolumn{2}{|c|}{ Formula Name } & & & \multirow{2}{*}{$\begin{array}{c}\text { Batch size } \\
500\end{array}$} & \multirow[b]{2}{*}{ grams } \\
\hline & Red Nail polish & & & & \\
\hline & Purpose & INGREDIENT & $\%$ & $\begin{array}{l}\text { Amt. In } \\
\text { Batch } \\
\end{array}$ & Actual Amt. \\
\hline 1 & Solvent & Buty Acetate & 27.000 & 135.00 & \\
\hline 2 & Solvent & Etyhl Acetate & 23.200 & 116.00 & \\
\hline 3 & Solvent & Toluene & 12.000 & 60.00 & \\
\hline 4 & Film former & Nitrocellulose ( $30 \%$ active IPA) & 13.000 & 65.00 & \\
\hline 5 & Resin & Tosylamidefformaldehyde Resin & 9.000 & 45.00 & \\
\hline 6 & Plasticizer & Dibuty Phthalate & 7.000 & 35.00 & \\
\hline 7 & Solvent & Isopropyl Alcohol & 5.000 & 25.00 & \\
\hline 8 & Thickener & Stearalkonium Hectorite & 1.500 & 7.50 & \\
\hline 9 & Plasticizer & Camphor & 0.950 & 4.75 & \\
\hline 10 & Antioxidant & Benzophenone-1 & 0.150 & 0.75 & \\
\hline 11 & Color & Titanium dioxide & 0.500 & 2.50 & \\
\hline 12 & Color & Red no 7 (Ca Lake) & 0.500 & 2.50 & \\
\hline 13 & Color & Red no 34 (Ca Lake) & 0.200 & 1.00 & \\
\hline & & & & & \\
\hline & & TOTAL & 100.000 & 500.00 & \\
\hline & Procedure: & & & & \\
\hline & & & & & \\
\hline & 1. Combine items $\# 1,2,3 \mathrm{i}$ & container & & & \\
\hline & 2. Dissolve item \#4 \& \#5 & & & & \\
\hline & 3. Separately blend colors & $\# 11,12,13$ ) in item \#6 in a grinder mill & & & \\
\hline & 4. Add belnd to main batch & emaining ingredients & & & \\
\hline
\end{tabular}

VIII. MEDICATED NAIL LACQUERS.

8.1 Ciclopirox Nail Lacquer 8\% for the Treatment of Onychomycosis:

Onychomycosis is prevalent in the Canadian population, and risk factors, such as old age and diabetes, are increasing. This condition has traditionally been treated using oral antifungal agents with varying degrees of success. Recently, ciclopirox nail lacquer $8 \%$ solution became the first topical agent approved in Canada for onychomycosis. Ciclopirox nail lacquer may be safe and effective for the treatment of onychomycosis, and certain candidates may benefit from therapy. Ciclopirox may be implicated for prophylactic use in order to 
prevent recurrent infection and may be used in combination with oral agents.Demographic studies suggest that onychomycosis affects between $6.1 \%$ and $6.9 \%$ of the Canadian population. Several risk factors are associated with the development of onychomycosis, including male gender, increasing age, diabetes, peripheral vascular disease, and immunosuppression. With the increasing age of the Canadian population and the high incidence of diabetes, a set of safe and effective options for the treatment of this condition is needed.

Ciclopirox $8 \%$ solution is the only topical antifungal approved for onychomycosis in Canada. This compound is fungicidal in vitro against proliferating and dormant fungal cells, and has a broad spectrum of activity. Ciclopirox nail lacquer was recently approved in Canada (April 2004) as part of a comprehensive nail management program, in which the lacquer is applied once daily for 48 weeks and nail debridement is performed under the supervision of a medical professional. Ciclopirox targets a variety of metabolic processes in the fungal cell. It chelates polyvalent cations $(\mathrm{Fe}+3$ and $\mathrm{Al}+3)$ that are involved in fungal enzymatic activity, ultimately interrupting intracellular energy production and toxic peroxide degradation. Ciclopirox may also inhibit fungal nutrient uptake, resulting in a depletion of amino acids and nucleotides and a reduction in protein synthesis.

Ciclopirox nail lacquer penetrates the nail plate via a transungual delivery system. When the solvent evaporates the concentration of ciclopirox increases from $8 \%$ to $34.8 \%$, providing a concentration gradient that facilitates the transfer of the drug through the nail plate. This mode of application permits distribution of the active compound throughout the entire nail plate, including the lateral margins and onycholytic portions of the nail. In vitro penetration studies in pigskin, cow horn, sheep hoof plates, and human nailsusing radiolabelled ciclopirox demonstrated penetration of the active ingredient as deep as $0.4 \mathrm{~mm}$ into the nail after one application. Pharmacological studies demonstrate that ciclopirox nail lacquer, applied daily for 7-14 days, penetrates the nail at concentrations that exceed the in vitro minimum inhibitory concentrations (MICs) for most fungal species.

Drug-Drug Interactions : Ciclopirox has no reported interactions with other systemic drugs. Ciclopirox treatment-emergent adverse events (TEAE) reported in US pivotal trials were localized to the treatment area. Nine percent of patients treated with ciclopirox nail lacquer and $7 \%$ of patients treated with vehicle reported TEAEs considered by the investigator to be related to the test material. The most common TEAE was a mild rash at the application site (5\% ciclopirox, $1 \%$ vehicle). Other attributable TEAEs included nail disorders such as shape change, irritation, ingrown toenail, and discolouration. Low levels of ciclopirox are recovered systemically. The mean systemic absorption of ciclopirox is less than $5 \%$ of the applied dose.

In Vitro: The efficacy of ciclopirox has been demonstrated in vitro against a broad spectrum of proliferating and dormant fungal strains. The MIC (mean \pm SEM) for ciclopirox was $0.04 \pm 0.02 \mathrm{mgml}^{-1}$ against dermatophytes, $0.05 \pm 0.02 \mathrm{mgml}^{-1}$ against yeasts, and $1.04 \pm 2.62 \mathrm{mgml}^{-1}$ against other nondermatophytes.

In Vivo: Two double-blind, vehicle-controlled, multicenter pivotal US clinical trials assessing the use of ciclopirox nail lacquer for mild-to-moderate onychomycosis (20\%-65\% surface area involvement of the target toenail) demonstrated significant mycological efficacy of the active compound when compared with the vehicle. The mycological cure (negative $\mathrm{KOH}$ and culture) rate for ciclopirox nail lacquer applied once daily for 48 weeks was $29 \%$ (ciclopirox) vs. $11 \%$ (vehicle) in the first trial and $36 \%$ (ciclopirox) vs. 9\% (vehicle) in the second trial. Data from a meta-analysis of 10 trials conducted worldwide showed a mean $( \pm \mathrm{SE})$ mycological cure rate of $52.6 \% \pm 4.2 \%$ (range: $46.7 \%-85.7 \%$ ). Although the parameters of these studies were different, these results were consistent with the US results. These studies and US pivotal trials establish the efficacy of ciclopirox nail lacquer for the treatment of onychomycosis.

Successful treatment of onychomycosis caused by nondermatophyte molds with ciclopirox nail lacquer has been reported. These results demonstrate the broad spectrum of activity of ciclopirox nail lacquer in vivo. Ciclopirox has demonstrated synergy in vitro when combined with oral agents. Synergy between ciclopirox and terbinafine was demonstrated in vitro against 5 of 6 nondermatophyte species tested. Synergy, additivism, and indifference were observed between ciclopirox and itraconazole. No antagonism was observed for either combination. Mycological cure rates in patients receiving 8 weeks of terbinafine $(250 \mathrm{mg} /$ day) plus ciclopirox nail lacquer (once daily for 48 weeks) compared with patients receiving 12 weeks of terbinafinemonotherapy $(250 \mathrm{mg} /$ day) suggest that combination therapy of ciclopirox nail lacquer with lower doses of terbinafine may be effective. At the end of 48 weeks, mycological cure was reported in $66.7 \%$ of patients treated for 8 weeks with terbinafine and ciclopirox, $70.4 \%$ of patients receiving 12 weeks terbinafine and ciclopirox, and $56.0 \%$ for those treated with 12 weeks of terbinafine alone ( $p>0.05)$. 
Patients not eligible for systemic treatment due to safety issues (i.e., the elderly and patients with hepatic dysfunction), those using multiple medications, or patients unwilling to use systemic treatment are candidates for topical antifungal therapy using ciclopirox nail lacquer. In patients with onycholysis, the lacquer may penetrate to onycholytic regions that may not receive adequate drug from conventional oral therapy. In cases of dermatophytoma, a subungual mass of densely packed thick-walled fungal hyphae, a combined approach of oral/topical/mechanical therapies may increase efficacy rates. In lateral onychomycosis, the concentration of the oral antifungal agent is lower in the lateral portion of the nail plate, and combining it with ciclopirox nail lacquer may help improve efficacy by providing drug to this area of the nail. Patients may benefit from the use of ciclopirox nail lacquer applied twice weekly as a means of preventing recurrence. However, the benefit of prophylactic treatment needs to be confirmed in controlled trials.Pharmaco-economic analysis suggests that ciclopirox nail lacquer may be a cost-effective option for the management of dermatophyteonychomycosis. The wholesale price of the lacquer in Canada is $\$ 89.95 / 6 \mathrm{~g}$ bottle, which offers more than 1,000 applications. Ciclopirox nail lacquer is the only approved topical agent for the treatment of mild-to-moderate onychomycosis. The choice of antifungal therapy depends on several factors: efficacy, spectrum of activity, convenience, cost, and patient/physician preference.

\section{CLINICAL PHARMACOLOGY}

\section{Microbiology}

Mechanism of Action : The mechanism of action of ciclopirox has been investigated using various in vitro and in vivo infection models. One in vitro study suggested that ciclopirox acts by chelation of polyvalent cations $(\mathrm{Fe}+3$ or $\mathrm{Al}+3)$ resulting in the inhibition of the metal-dependent enzymes that are responsible for the degradation of peroxides within the fungal cell. The clinical significance of this observation is not known.Activity in vitro and ex vivo In vitro methodologies employing various broth or solid media with and without additional nutrients have been utilized to determine ciclopirox minimum inhibitory concentration (MIC) values for the dermatophytic molds.(1-2) As a consequence, a broad range of MIC values, 1-20 $\mu \mathrm{g} / \mathrm{mL}$, were obtained for Trichophytonrubrum and Trichophytonmentagrophytes species. Correlation between in vitro MIC results and clinical outcome has yet to be established for ciclopirox. One ex vivo study was conducted evaluating 8\% ciclopirox against new and established Trichophytonrubrum and Trichophytonmentagrophytes infections in ovine hoof material.(3) After 10 days of treatment the growth of T. rubrum and T. mentagrophytes in the established infection model was very minimally affected. Elimination of the molds from hoof material was not achieved in either the new or established infection models. Susceptibility testing for Trichophytonrubrum species In vitro susceptibility testing methods for determining ciclopirox MIC values against the dermatophytic molds, including Trichophytonrubrum species, have not been standardized or validated. Ciclopirox MIC values will vary depending on the susceptibility testing method employed, composition and $\mathrm{pH}$ of media and the utilization of nutritional supplements. Breakpoints to determine whether clinical isolates of Trichophytonrubrum are susceptible or resistant to ciclopirox have not been established.

Resistance : Studies have not been conducted to evaluate drug resistance development in T. rubrum species exposed to $8 \%$ ciclopirox topical solution. Studies assessing cross-resistance to ciclopirox and other known antifungal agents have not been performed.

Antifungal Drug Interactions : No studies have been conducted to determine whether ciclopirox might reduce the effectiveness of systemic antifungal agents for onychomycosis. Therefore, the concomitant use of $8 \%$ ciclopirox topical solution and systemic antifungal agents for onychomycosis is not recommended.

Pharmacokinetics : As demonstrated in pharmacokinetic studies in animals and man, ciclopiroxolamine is rapidly absorbed after oral administration and completely eliminated in all species via feces and urine. Most of the compound is excreted either unchanged or as glucuronide. After oral administration of $10 \mathrm{mg}$ of radiolabeled drug (14C-ciclopirox) to healthy volunteers, approximately $96 \%$ of the radioactivity was excreted renally within 12 hours of administration. Ninety-four percent of the renally excreted radioactivity was in the form of glucuronides. Thus, glucuronidation is the main metabolic pathway of this compound.Systemic absorption of ciclopirox was determined in 5 patients with dermatophyticonychomycoses, after application of ciclopirox topical solution, $8 \%$ (nail lacquer), to all 20 digits and adjacent $5 \mathrm{~mm}$ of skin once daily for six months. Random serum concentrations and 24 hour urinary excretion of ciclopirox were determined at two weeks and at 1, 2, 4 and 6 months after initiation of treatment and 4 weeks post-treatment. In this study, ciclopirox serum levels ranged from $12-80 \mathrm{ng} / \mathrm{mL}$. Based on urinary data, mean absorption of ciclopirox from the dosage form was $<5 \%$ of the applied dose. One month after cessation of treatment, serum and urine levels of ciclopirox were below the limit of detection. 
In two vehicle-controlled trials, patients applied ciclopirox topical solution, $8 \%$ (nail lacquer), to all toenails and affected fingernails. Out of a total of 66 randomly selected patients on active treatment, 24 had detectable serum ciclopirox concentrations at some point during the dosing interval (range 10.0-24.6 ng/mL). It should be noted that eleven of these 24 patients took concomitant medication containing ciclopirox as ciclopiroxolamine (Loprox ${ }^{\circledR}$ Cream, 0.77\%). The penetration of the ciclopirox topical solution, 8\% (nail lacquer), was evaluated in an in vitro investigation. Radiolabeled ciclopirox applied once to onychomycotic toenails that were avulsed demonstrated penetration up to a depth of approximately $0.4 \mathrm{~mm}$. As expected, nail plate concentrations decreased as a function of nail depth. The clinical significance of these findings in nail plates is unknown. Nail bed concentrations were not determined.

\section{Indications \& usage}

Ciclopirox topical solution, 8\% (nail lacquer), as a component of a comprehensive management program, is indicated as topical treatment in immunocompetent patients with mild to moderate onychomycosis of fingernails and toenails without lunula involvement, due to Trichophytonrubrum. The comprehensive management program includes removal of the unattached, infected nails as frequently as monthly, by a health care professional who has special competence in the diagnosis and treatment of nail disorders, including minor nail procedures.

- No studies have been conducted to determine whether ciclopirox might reduce the effectiveness of systemic antifungal agents for onychomycosis. Therefore, the concomitant use of ciclopirox topical solution, 8\% (nail lacquer) and systemic antifungal agents for onychomycosis, is not recommended.

- Ciclopirox topical solution, $8 \%$ (nail lacquer), should be used only under medical supervision as described above.

- The effectiveness and safety of ciclopirox topical solution, 8\% (nail lacquer), in the following populations has not been studied. The clinical trials with use of ciclopirox topical solution, $8 \%$ (nail lacquer), excluded patients who: were pregnant or nursing, planned to become pregnant, had a history of immunosuppression (e.g., extensive, persistent, or unusual distribution of dermatomycoses, extensive seborrheic dermatitis, recent or recurring herpes zoster, or persistent herpes simplex), were HIV seropositive, received organ transplant, required medication to control epilepsy, were insulin dependent diabetics or had diabetic neuropathy. Patients with severe plantar (moccasin) tineapedis were also excluded.

- The safety and efficacy of using ciclopirox topical solution, $8 \%$ (nail lacquer), daily for greater than 48 weeks have not been establishe. ${ }^{[26]}$

\subsection{Amorolfine nail lacquer :}

- Amorolfine is an antifungal used for fungal infections of the finger and toe nails.

- Amorolfine lacquer is usually applied once or twice a week, after filing and cleaning the nails.

- Amorolfine occasionally causes side-effects including skin irritation such as redness, itching, or a burning sensation.

\section{About amorolfine nail lacquer \\ Type.of medicine Antifungal \\ Used for Fungal infections of the finger and toe nails \\ Also called $\quad$ Loceryl ${ }^{\circledR}$, Curanail $®$}

Fungal infections may be caught from another person, from an animal, from soil, from the floors of showers, or from household objects such as chairs or carpets. The appearance and symptoms of fungal infections vary according to where the infection is. When the nails are infected they become thickened, discoloured and crumble when cut.

\section{Before using amorolfine nail lacquer}

Before using amorolfine nail lacquer make sure your doctor or pharmacist knows:

- If you are pregnant, trying for a baby or breast-feeding.

- If you have ever had an allergic reaction to this or to any other medicine.

\section{How to use amorolfine nail lacquer}

- Amorolfine lacquer is usually applied once or twice a week.

- Treatment should continue until the infection has cleared and healthy nails have regrown. This usually takes 6 months for finger nail infections and up to 12 months for toe nail infections.

- Do not use nail varnish or artificial nails while you are being treated with amorolfine. 
- Do not allow amorolfine lacquer to come into contact with your eyes, ears, or mucous membranes (eg. mouth, vagina, inside of nose etc).

- If you use any chemicals such as thinners or white spirits, wear waterproof gloves to protect the lacquer on your finger nails.

Can amorolfine nail lacquer cause problems : Along with their useful effects, all medicines can cause unwanted side-effects although not everyone experiences them. Speak with your doctor or pharmacist if any of the following side-effects continue or become troublesome.

\section{Rare side-effects}

Skin redness, itching, or a burning

sensation

Nail discolouration

\section{How to store amorolfine nail lacquer}

- Keep all medicines out of the reach and sight of children.

- Store in a cool, dry place, away from direct heat and light.

\section{Important information about all medicines}

- If you suspect that someone has swallowed some of this medicine, go to the accident and emergency department of your local hospital at once. Take the container with you, even if it is empty.

- Always read the printed information leaflet that comes with your medicine.

- This medicine is for you. Never give it to other people even if their condition appears to be the same as yours.

- Never keep out-of-date or unwanted medicines. Take them to your local pharmacy which will dispose of them for you.

- If you have any questions about this medicine ask your pharmacist.

83 Curanail 5\% w/w Medicated Nail Lacquer

1. Name Of The Medicinal Product

Curanail 5\%w/v Medicated Nail Lacquer

\section{Qualitative And Quantitative Composition}

Curanail 5\% nail lacquer contains $5 \% \mathrm{w} / \mathrm{v}$ amorolfine in the form of hydrochloride. Amorolfine is chemically described as cis-4-[(RS)-3[4-(1,1-Dimethylpropyl)phenyl]-2-methylpropyl]-2,6-dimethylmorpholine.

Amorolfine hydrochloride HSE $6.40 \%$ w/w

For a full list of excipients, see section 6.1

3. Pharmaceutical Form

Medicated Nail Lacquer.

4. Clinical Particulars

4.1 therapeutic indications

Treatment of mild cases of distal and lateral subungualonychomycoses caused by dermatophytes, yeasts and moulds limited up to 2 nails.

\section{2 posology and method of administration}

Adults and Elderly

The nail lacquer should be applied to the affected finger or toe nails once weekly.

The patient should apply the nail lacquer as follows:

Before the first application of Curanail 5\% nail lacquer, it is essential that the affected areas of nail (particularly the nail surfaces) should be filed down as thoroughly as possible using a nail file, as supplied. The surface of the nail should then be cleansed and degreased using an alcohol cleaning pad, as supplied. Before repeat application of Curanail 5\% nail lacquer, the affected nails should be filed down again as required, following cleansing with a cleaning pad to remove any remaining lacquer. 
Caution: Nail files used for affected nails must not be used for healthy nails.

With one of the reusable applicators supplied, apply the nail lacquer to the entire surface of the affected nails and allow it to dry. After use, clean the applicator with the same cleaning pad used before for nail cleaning. Keep the bottle tightly closed. For each nail to be treated, dip the applicator into the nail lacquer without wiping off any of the lacquer on the bottle neck. Caution: When working with organic solvents (thinners, white spirit, etc.) wear impermeable gloves in order to protect the Curanail 5\% nail lacquer on the nails. Treatment should be continued without interruption until the nail is regenerated and the affected areas are finally cured. The required frequency and duration of treatment depends essentially on intensity and localisation of the infection. In general, it is six months (finger nails) and nine to twelve months (toe nails). A review of the treatment is recommended at intervals of approximately three months. Co-existent tineapedis should be treated with an appropriate antimycotic cream.

Children : Due to the lack of clinical experience available, Curanail 5\% nail lacquer is not recommended for patients below the age of 18 years.

\subsection{Contraindications}

Curanail 5\% nail lacquer must not be reused by patients who have shown hypersensitivity to the active substance or to any of the excipients. No experience exists of use during pregnancy and nursing, therefore, the use of Curanail 5\% nail lacquer should be avoided during pregnancy and lactation.

\section{4 special warnings and precautions for use}

Avoid contact of the lacquer with eyes, ears and mucous membranes. Patients with underlying conditions predisposing to fungal nail infections should be referred to a doctor. Such conditions include peripheral circulatory disorders, diabetes mellitus, and immunosuppression. Patients with nail dystrophy and destroyed nail plate should be referred to their doctor.

\section{5 interaction with other medicinal products and other forms of interaction}

There are no specific studies involving concomitant treatment with other topical medicines. Use of nail varnish or artificial nails should be avoided during treatment. 4.6 Pregnancy and lactation Reproductive toxicology studies showed no evidence of teratogenicity in laboratory animals but embryotoxicity was observed at high oral doses. The systemic absorption of amorolfine during and after topical administration is very low and therefore the risk to the human foetus appears to be negligible. However, because there is no relevant experience, Curanail 5\% nail lacquer should be avoided during pregnancy and breast feeding.

\subsection{Effects On Ability To Drive And Use Machines}

Not relevant.

\subsection{Undesirable Effects}

Adverse drug reactions are rare. Nail disorders (e.g. nail discoloration, broken nails, brittle nails) may occur. These reactions can also be linked to the onychomycosis itself.

\begin{tabular}{|l|l|l|}
\hline System Organ Class & Frequency & Adverse drug reaction \\
\hline Skin and subcutaneous tissue disorders & Rare $(\geq 1 / 10000,<1 / 1000)$ & $\begin{array}{l}\text { Nail disorder, nail discoloration, } \\
\text { nnychoclasis } \begin{array}{c}\text { nails), } \\
\text { (broken } \\
\text { onychorrhexis (brittle nails) }\end{array}\end{array}$ \\
\hline Very rare $(<1 / 10000)$ & Skin burning sensation & \\
\cline { 1 - 2 }
\end{tabular}

Contact dermatitis (unknown frequency) has been reported in spontaneous reports.

\subsection{Overdose}

Accidental oral ingestion.

Curanail 5\% nail lacquer is for topical use. In the event of accidental oral ingestion, an appropriate method of gastric emptying may be used. ${ }^{[21]}$

\subsection{Penlanail lacquer}

Description : Penlac ${ }^{\circledR}$ nail lacquer (ciclopirox) Topical Solution, 8\%, contains a synthetic antifungal agent, ciclopirox. It is intended for topical use on fingernails and toenails and immediately adjacent skin. Each gram of penlac $^{\circledR}$ nail lacquer (ciclopirox) Topical Solution, 8\%, contains $80 \mathrm{mg}$ ciclopirox in a solution base consisting 
of ethyl acetate, NF; isopropyl alcohol, USP; and butyl monoester of poly[methylvinyl ether/maleic acid] in isopropyl alcohol. Ethyl acetate and isopropyl alcohol are solvents that vaporize after application.

Penlac ${ }^{\circledR}$ nail lacquer (ciclopirox) Topical Solution, $8 \%$, is a clear, colorless to slightly yellowish solution.

The chemical name for ciclopirox is 6-cyclohexyl-1-hydroxy-4-methyl-2(1H)-pyridone, with the empirical formula $\mathrm{C}_{12} \mathrm{H}_{17} \mathrm{NO}_{2}$ and a molecular weight of 207.27. The CAS Registry Number is [29342-05-0]. The chemical structure is:<smiles>Cc1cc(C2CCCCC2)n(O)c(=O)c1</smiles>

Clinical pharmacology

\section{Microbiology}

Mechanism of Action : The mechanism of action of ciclopirox has been investigated using various in vitro and in vivo infection models. One in vitro study suggested that ciclopirox acts by chelation of polyvalent cations $\left(\mathrm{Fe}^{+3}\right.$ or $\left.\mathrm{Al}^{+3}\right)$ resulting in the inhibition of the metal-dependent enzymes that are responsible for the degradation of peroxides within the fungal cell. The clinical significance of this observation is not known.

Activity in vitro and in vivo : In vitro methodologies employing various broth or solid media with and without additional nutrients have been utilized to determine ciclopirox minimum inhibitory concentration (MIC) values for the dermatophytic molds. ${ }^{(1-2)}$ As a consequence, a broad range of MIC values, 1-20 ug/mL, were obtained for Trichophytonrubrumand Trichophytonmentagrophytes species. Correlation between in vitro MIC results and clinical outcome has yet to be established for ciclopirox. One ex vivo study was conducted evaluating $8 \%$ ciclopirox against new and established Trichophytonrubrum and Trichophytonmentagrophytes infections in ovine hoof material. ${ }^{(3)}$ After 10 days of treatment the growth of T. rubrum and $\mathrm{T}$. mentagrophytesin the established infection model was very minimally affected. Elimination of the molds from hoof material was not achieved in either the new or established infection models.

Susceptibility testing for Trichophytonrubrum species : In vitro susceptibility testing methods for determining ciclopirox MIC values against the dermatophytic molds, including Trichophytonrubrum species, have not been standardized or validated. Ciclopirox MIC values will vary depending on the susceptibility testing method employed, composition and $\mathrm{pH}$ of media and the utilization of nutritional supplements. Breakpoints to determine whether clinical isolates of Trichophytonrubrum are susceptible or resistant to ciclopirox have not been established.

Resistance : Studies have not been conducted to evaluate drug resistance development in T. rubrum species exposed to $8 \%$ ciclopirox topical solution. Studies assessing cross-resistance to ciclopirox and other known antifungal agents have not been performed.

Antifungal Drug Interactions :No studies have been conducted to determine whether ciclopirox might reduce the effectiveness of systemic antifungal agents for onychomycosis. Therefore, the concomitant use of $8 \%$ ciclopirox topical solution and systemic antifungal agents for onychomycosis is not recommended.

Pharmacokinetics : As demonstrated in pharmacokinetic studies in animals and man, ciclopiroxolamine is rapidly absorbed after oral administration and completely eliminated in all species via feces and urine. Most of the compound is excreted either unchanged or as glucuronide. After oral administration of $10 \mathrm{mg}$ of radiolabeled drug (14C-ciclopirox) to healthy volunteers, approximately $96 \%$ of the radioactivity was excreted renally within 12 hours of administration. Ninety-four percent of the renally excreted radioactivity was in the form of glucuronides. Thus, glucuronidation is the main metabolic pathway of this compound.Systemic absorption of ciclopirox was determined in 5 patients with dermatophyticonychomycoses, after application of penlac ${ }^{\circledR}$ nail lacquer (ciclopirox) Topical Solution, 8\%, to all 20 digits and adjacent $5 \mathrm{~mm}$ of skin once daily for six months. Random serum concentrations and 24 hour urinary excretion of ciclopirox were determined at two weeks and at 1, 2, 4 and 6 months after initiation of treatment and 4 weeks post-treatment. In this study, ciclopirox serum levels ranged from 12-80 ng/mL. Based on urinary data, mean absorption of ciclopirox from the dosage form 
was $<5 \%$ of the applied dose. One month after cessation of treatment, serum and urine levels of ciclopirox were below the limit of detection. In two vehicle-controlled trials, patients applied penlac ${ }^{\circledR}$ nail lacquer (ciclopirox) Topical Solution, $8 \%$, to all toenails and affected fingernails. Out of a total of 66 randomly selected patients on active treatment, 24 had detectable serum ciclopirox concentrations at some point during the dosing interval (range 10.0-24.6 ng/mL). It should be noted that eleven of these 24 patients took concomitant medication containing ciclopirox as ciclopiroxolamine (Loprox ${ }^{\circledR}$ Cream, 0.77\%).The penetration of the penlac ${ }^{\circledR}$ nail lacquer (ciclopirox) Topical Solution, 8\%, was evaluated in an in vitro investigation. Radiolabeled ciclopirox applied once to onychomycotic toenails that were avulsed demonstrated penetration up to a depth of approximately 0.4 $\mathrm{mm}$. As expected, nail plate concentrations decreased as a function of nail depth. The clinical significance of these findings in nail plates is unknown. Nail bed concentrations were not determined.

\section{Indications and usage}

Penlac $^{\circledR}$ nail lacquer (ciclopirox) Topical Solution, 8\%, as a component of a comprehensive management program, is indicated as topical treatment in immunocompetent patients with mild to moderate onychomycosis of fingernails and toenails without lunula involvement, due to Trichophytonrubrum. The comprehensive management program includes removal of the unattached, infected nails as frequently as monthly, by a health care professional who has special competence in the diagnosis and treatment of nail disorders, including minor nail procedures. No studies have been conducted to determine whether ciclopirox might reduce the effectiveness of systemic antifungal agents for onychomycosis. Therefore, the concomitant use of $8 \%$ ciclopirox topical solution and systemic antifungal agents for onychomycosis, is not recommended.Penlac ${ }^{\circledR}$ nail lacquer (ciclopirox) Topical Solution, $8 \%$, should be used only under medical supervision as described above.The effectiveness and safety of penlac ${ }^{\circledR}$ nail lacquer (ciclopirox) Topical Solution, $8 \%$, in the following populations has not been studied. The clinical trials with use of penlac ${ }^{\circledR}$ nail lacquer (ciclopirox) Topical Solution, $8 \%$, excluded patients who: were pregnant or nursing, planned to become pregnant, had a history of immunosuppression (e.g., extensive, persistent, or unusual distribution of dermatomycoses, extensive seborrheic dermatitis, recent or recurring herpes zoster, or persistent herpes simplex), were HIV seropositive, received organ transplant, required medication to control epilepsy, were insulin dependent diabetics or had diabetic neuropathy. Patients with severe plantar (moccasin) tineapedis were also excluded.The safety and efficacy of using penlac ${ }^{\circledR}$ nail lacquer (ciclopirox) Topical Solution, $8 \%$, daily for greater than 48 weeks have not been established.

Contraindications : Penlac ${ }^{\circledR}$ nail lacquer (ciclopirox) Topical Solution, 8\%, is contraindicated in individuals who have shown hypersensitivity to any of its components.

Warnings : Penlac ${ }^{\circledR}$ nail lacquer (ciclopirox) Topical Solution, 8\%, is not for ophthalmic, oral, or intravaginal use. For use on nails and immediately adjacent skin only.

Precautions : If a reaction suggesting sensitivity or chemical irritation should occur with the use of penlac ${ }^{\circledR}$ nail lacquer (ciclopirox) Topical Solution, 8\%, treatment should be discontinued and appropriate therapy instituted. So far there is no relevant clinical experience with patients with insulin dependent diabetes or who have diabetic neuropathy. The risk of removal of the unattached, infected nail, by the health care professional and trimming by the patient should be carefully considered before prescribing to patients with a history of insulin dependent diabetes mellitus or diabetic neuropathy.

Carcinogenesis, Mutagenesis, Impairment of Fertility: No carcinogenicity study was conducted with penlac ${ }^{\circledR}$ nail lacquer (ciclopirox) Topical Solution, 8\%, formulation. A carcinogenicity study of ciclopirox (1\% and 5\% solutions in polyethylene glycol 400) in female mice dosed topically twice per week for 50 weeks followed by a 6-month drug-free observation period prior to necropsy revealed no evidence of tumors at the application sites. In human systemic tolerability studies following daily application $\left(\sim 340 \mathrm{mg}\right.$ of penlac ${ }^{\circledR}$ nail lacquer (ciclopirox) Topical Solution, $8 \%$ ) in subjects with distal subungualonychomycosis, the average maximal serum level of ciclopirox was $31 \pm 28 \mathrm{ng} / \mathrm{mL}$ after two months of once daily applications. This level was 159 times lower than the lowest toxic dose and 115 times lower than the highest nontoxic dose in rats and dogs fed 7.7 and $23.1 \mathrm{mg}$ ciclopirox (as ciclopiroxolamine) $/ \mathrm{kg} /$ day. The following in vitrogenotoxicity tests have been conducted with ciclopirox: evaluation of gene mutation in Ames Salmonella and E. coli assays (negative); chromosome aberration assays in V79 Chinese hamster lung fibroblasts, with and without metabolic activation (positive); gene mutation assay in the HGPRT-test with V79 Chinese hamster lung fibroblasts (negative); unscheduled DNA synthesis in human A549 cells (negative); and BALB/c3T3 cell transformation assay (negative). In an in vivo Chinese hamster bone marrow cytogenetic assay, ciclopirox was negative for chromosome aberrations at $5,000 \mathrm{mg} / \mathrm{kg}$. 
The following in vitrogenotoxicity tests were conducted with penlac ${ }^{\circledR}$ nail lacquer (ciclopirox) Topical Solution, $8 \%$ : Ames Salmonella test (negative); unscheduled DNA synthesis in the rat hepatocytes (negative); cell transformation assay in BALB/c3T3 cell assay (positive). The positive response of the lacquer formulation in the BALB/c3T3 test was attributed to its butyl monoester of poly[methylvinyl ether/maleic acid] resin component (Gantrez ${ }^{\circledR}$ ES-435), which also tested positive in this test. The cell transformation assay may have been confounded because of the film-forming nature of the resin. Gantrez ${ }^{\circledR}$ ES-435 tested nonmutagenic in both the in vitro mouse lymphoma forward mutation assay with or without activation and unscheduled DNA synthesis assay in rat hepatocytes.

Oral reproduction studies in rats at doses up to $3.85 \mathrm{mg}$ ciclopirox (as ciclopiroxolamine) $/ \mathrm{kg} / \mathrm{day}$ [equivalent to approximately 1.4 times the potential exposure at the maximum recommended human topical dose (MRHTD)] did not reveal any specific effects on fertility or other reproductive parameters. MRHTD $\left(\mathrm{mg} / \mathrm{m}^{2}\right)$ is based on the assumption of $100 \%$ systemic absorption of $27.12 \mathrm{mg}$ ciclopirox $\left(\sim 340 \mathrm{mg}\right.$ penlac ${ }^{\circledR}$ nail lacquer (ciclopirox) Topical Solution, 8\%) that will cover all the fingernails and toenails including $5 \mathrm{~mm}$ proximal and lateral fold area plus onycholysis to a maximal extent of $50 \%$.

\section{Pregnancy: Teratogenic effects: Pregnancy Category B}

Teratology studies in mice, rats, rabbits, and monkeys at oral doses of up to $77,23,23$, or $38.5 \mathrm{mg}$, respectively, of ciclopirox as ciclopiroxolamine $/ \mathrm{kg} /$ day $(14,8,17$, and 28 times MRHTD), or in rats and rabbits receiving topical doses of up to 92.4 and $77 \mathrm{mg} / \mathrm{kg} / \mathrm{day}$, respectively (33 and 55 times MRHTD), did not indicate any significant fetal malformations. There are no adequate or well-controlled studies of topically applied ciclopirox in pregnant women. Penlac ${ }^{\circledR}$ nail lacquer (ciclopirox) Topical Solution, $8 \%$, should be used during pregnancy only if the potential benefit justifies the potential risk to the fetus.

Nursing Mothers:It is not known whether this drug is excreted in human milk. Since many drugs are excreted in human milk, caution should be exercised when penlac ${ }^{\circledR}$ nail lacquer (ciclopirox) Topical Solution, 8\%, is administered to a nursing woman.

Pediatric Use:Based on the safety profile in adults, penlac ${ }^{\circledR}$ nail lacquer (ciclopirox) Topical Solution, $8 \%$ is considered safe for use in children twelve years and older. No clinical trials have been conducted in the pediatric population.

Geriatric Use:Clinical studies of penlac ${ }^{\circledR}$ nail lacquer (ciclopirox) Topical Solution, 8\%, did not include sufficient numbers of subjects aged 65 and over to determine whether they respond differently from younger subjects. Other reported clinical experience has not identified differences in responses between elderly and younger patients.

Adverse reactions : In the vehicle-controlled clinical trials conducted in the US, 9\% (30/327) of patients treated with penlac ${ }^{\circledR}$ nail lacquer (ciclopirox) Topical Solution, $8 \%$, and 7\% (23/328) of patients treated with vehicle reported treatment-emergent adverse events (TEAE) considered by the investigator to be causally related to the testmaterial.The incidence of these adverse events, within each body system, was similar between the treatment groups except for Skin and Appendages: 8\% (27/327) and 4\% (14/328) of subjects in the ciclopirox and vehicle groups reported at least one adverse event, respectively. The most common were rash-related adverse events: periungual erythema and erythema of the proximal nail fold were reported more frequently in patients treated with penlac ${ }^{\circledR}$ nail lacquer (ciclopirox) Topical Solution, 8\%, (5\% [16/327]) than in patients treated with vehicle (1\% [3/328]). Other TEAEs thought to be causally related included nail disorders such as shape change, irritation, ingrown toenail, and discoloration. The incidence of nail disorders was similar between the treatment groups (2\% [6/327] in the penlac ${ }^{\circledR}$ nail lacquer (ciclopirox) Topical Solution, 8\%, group and 2\% [7/328] in the vehicle group). Moreover, application site reactions and/or burning of the skin occurred in $1 \%$ of patients treated with penlac ${ }^{\circledR}$ nail lacquer (ciclopirox) Topical Solution, 8\%, (3/327) and vehicle (4/328).

A 21-Day Cumulative Irritancy study was conducted under conditions of semi-occlusion. Mild reactions were seen in $46 \%$ of patients with the penlac ${ }^{\circledR}$ nail lacquer (ciclopirox) Topical Solution, $8 \%, 32 \%$ with the vehicle and $2 \%$ with the negative control, but all were reactions of mild transient erythema. There was no evidence of allergic contact sensitization for either the penlac ${ }^{\circledR}$ nail lacquer (ciclopirox) Topical Solution, $8 \%$, or the vehicle base. In a separate study of the photosensitization potential of penlac ${ }^{\circledR}$ nail lacquer (ciclopirox) Topical Solution, $8 \%$ in a maximized test design that included the occluded application of sodium lauryl sulfate, no photoallergic reactions were noted. In four subjects localized allergic contact reactions were observed. 
In the vehicle-controlled studies, one patient treated with penlac ${ }^{\circledR}$ nail lacquer (ciclopirox) Topical Solution, $8 \%$, discontinued treatment due to a rash, localized to the palm (causal relation to test material undetermined). Use of penlac ${ }^{\circledR}$ nail lacquer (ciclopirox) Topical Solution, 8\%, for 48 additional weeks was evaluated in an open-label extension study conducted in patients previously treated in the vehicle-controlled studies. Three percent (9/281) of subjects treated with penlac ${ }^{\circledR}$ nail lacquer (ciclopirox) Topical Solution, 8\%, experienced at least one TEAE that the investigator thought was causally related to the test material. Mild rash in the form of periungual erythema (1\% [2/281]) and nail disorders (1\% [4/281]) were the most frequently reported. Four patients discontinued because of TEAEs. Two of the four had events considered to be related to test material: one patient's great toenail "broke away" and another had an elevated creatine phosphokinase level on Day 1 (after 48 weeks of treatment with vehicle in the previous vehicle-controlled study).

Dosage and administration : Penlac ${ }^{\circledR}$ nail lacquer (ciclopirox) Topical Solution, 8\%, should be used as a component of a comprehensive management program for onychomycosis. Removal of the unattached, infected nail, as frequently as monthly, by a health care professional, weekly trimming by the patient, and daily application of the medication are all integral parts of this therapy. Careful consideration of the appropriate nail management program should be given to patients with diabetes.

Nail care by health care professionals: Removal of the unattached, infected nail, as frequently as monthly, trimming of onycholytic nail, and filing of excess horny material should be performed by professionals trained in treatment of nail disorders.

Nail care by patient: Patients should file away (with emery board) loose nail material and trim nails, as required, or as directed by the healthcare professional, every seven days after penlac ${ }^{\circledR}$ nail lacquer (ciclopirox) Topical Solution, $8 \%$, is removed with alcohol. Penlac ${ }^{\circledR}$ nail lacquer (ciclopirox) Topical Solution, $8 \%$, should be applied once daily (preferably at bedtime or eight hours before washing) to all affected nails with the applicator brush provided. The penlac ${ }^{\circledR}$ nail lacquer (ciclopirox) Topical Solution, $8 \%$, should be applied evenly over the entire nail plate.

If possible, penlac ${ }^{\circledR}$ nail lacquer (ciclopirox) Topical Solution, $8 \%$, should be applied to the nail bed, hyponychium, and the under surface of the nail plate when it is free of the nail bed (e.g., onycholysis). The penlac ${ }^{\circledR}$ nail lacquer (ciclopirox) Topical Solution, 8\%, should not be removed on a daily basis. Daily applications should be made over the previous coat and removed with alcohol every seven days. This cycle should be repeated throughout the duration of therapy.

Protect from light (e.g., store the bottle in the carton after every use).

Caution: Flammable. Keep away from heat and flame.

Patient Information and Instructions : Patients should have detailed instructions regarding the use of penlac ${ }^{\circledR}$ nail lacquer (ciclopirox) Topical Solution, 8\%, as a component of a comprehensive management program for onychomycosis in order to achieve maximum benefit with the use of this product. Discuss your treatment plan with your health care professional for regular removal of the unattached, infected nail.

\section{Patient instructions}

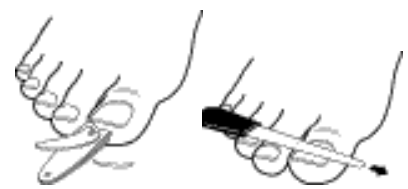

1.Before starting treatment, remove any loose nail or nail material using nail clippers or nail files. If you have diabetes or problems with numbness in your toes or fingers, talk to your health care provider before trimming your nails or removing any nail material.

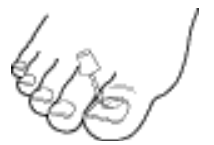

2.Apply penlac ${ }^{\circledR}$ nail lacquer (ciclopirox) Topical Solution, $8 \%$, once daily (preferably at bedtime) to all affected nails with the applicator 
brush provided. Apply the lacquer evenly over the entire nail. Where possible, nail lacquer should also be applied to the underside of the nail and to the skin beneath it. Allow lacquer to dry (approximately 30 seconds) before putting on socks or stockings. After applying medication, wait 8 hours before taking a bath or shower.

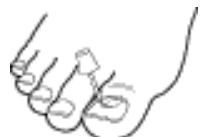

3.Apply penlac ${ }^{\circledR}$ nail lacquer (ciclopirox) Topical Solution, $8 \%$, daily over the previous coat.

4.Once a week, remove the penlac ${ }^{\circledR}$ nail lacquer (ciclopirox) Topical Solution, $8 \%$, with alcohol. Remove as much as possible of the damaged nail using scissors, nail clippers, or nail files.

\section{Repeat process (steps 2 through 4 ).}

\section{Please Note:}

1. To prevent screw cap from sticking to the bottle, do not allow

2. solution to get into the bottle threads.

3. To prevent the solution from drying out, bottle should be closed tightly after every use.

To protect from light, replace bottle into carton after each use. ${ }^{[10]}$

\subsection{Locery15\% 5ml Nail Lacquer}

Purpose: For the treatment of fungal nail infections

Ingredients : Active ingredients: Amorolfine, each $5 \mathrm{ml}$ bottle contains $250 \mathrm{mg}$ of amorolfine as the hydrochloride

Inactive ingredients: Each $5 \mathrm{ml}$ bottle also contains :methacrylic acid copolymer, glycerol triacetate, butyl acetate, ethyl acetate, absolute ethanol

How to use loceryl: Loceryl is intended for external use only. Loceryl should not be swallowed

Carefully follow the steps below before using loceryl:

Place everything you need for loceryl treatment within easy reach:

- Loceryl nail lacquer

- Nail file (supplied)

- Cleaning pad (supplied) reusable spatula (supplied)

2. Before painting with loceryl nail lacquer, file down the infected areas of the nail (particularly the nail surfaces) as thoroughly as possible using the nail file. Caution: nail files used on an infected nail must not be used on healthy nails.

3. Clean the surface of the infected nail with a cleaning pad

4. Dip one of the reusable spatulas into the lacquer. Do not wipe it on the neck of the bottle. NOTE: The spatula provides a measured dose of loceryl

5. Using the spatula, paintlocerylnail lacquer over the entire surface of the infected nail

6. Close the bottle tightly immediately after painting the infected nail

7. Repeat steps $2,3,4$ and 5 for each nail

8. Allow time for the nails to dry ( 3 to 5 minutes) 
9. When you have finished treating all of your infected nails, clean the spatula and the neck of the bottle with the same cleaning pad that we used during the treatment

Follow these steps each time you useloceryl

How often to apply loceryl

Paintlocerylonce or twice weekly on the infected fingernails or toenails or as otherwise directed by your doctor, or pharmacist

If you forget to paint on the loceryl nail lacquer, use it as soon as you remember.Then go back to using loceryl as you would normally

\section{How long loceryl should be used}

Treatment should be continued until the infected nails are completely cured and re-grown. Usually, treatment of fungal infections of the nails takes around six months for the fingernails and nine to twelve months for the toenails Don't be discouraged if after several weeks of therapy no improvement is visible. A healthy nail only grows by approximately $2 \mathrm{~mm}$ per month In case of accidental swallowing Immediately telephone your doctor or Poisons Information Centre or advice or go to Accident and Emergency at your nearest hospital if you think that you or anyone else may have swallowed loceryl, even if there are no signs of discomfort or poisoning. You may need urgent medical attention.

While you are using loceryl

Things you must do

If you are about to be started on a new medicine, tell your doctor, and pharmacist that you are using loceryl.

If you work with solvents (eg paint thinner, turpentine substitute, petrol, paraffin etc), wear gloves to protect the coat of nail lacquer on your fingernails

\section{Things you must not do}

Do not use nail files for infected nails on healthy nails

Do not use artificial nails during treatment with loceryl

Do not apply cosmetic nail varnish or other medication(s) on the nail(s) being treated

Do not give loceryl to anyone else to use, even if they have the same condition as you

Do not use loceryl to treat other complaints unless your doctor says to

Things to be careful of

Take care that loceryl does not come into contact with your skin

\section{Side affects:}

All medicines can have side effects.Loceryl helps most people with fungal infections of the nails but it may have unwanted side effects in a few people.

- burning feeling in the area surrounding the treated nail(s). This is usually mild and short-lasting

- itching or redness of the skin

Storage : Screw the bottle top of thelocerylnail lacquer tightly immediately after use Keep loceryl in a cool dry place where the temperature stays below 300 C.Heat and dampness can destroy some medicines Do not store it, or any other medicine, in a bathroom or near a sink Do not leave in the car or on windowsills Keep loceryl where young children cannot reach it. A locked cupboard at least one-and-a-half metres above the ground is a good place to store medicines

\section{Warnings:}

Keep out of reach of children

Store below 30c 
For external use only

Do not swallow

Applications-

- Onychomycosis disease treatment to use medicated nail lacquers.

- Onychomycosis disease treatment to use Ciclopirox Nail Lacquer $8 \%$.

- Distal and lateral subungual onychomycosis disease treatment to use amorofine containing Curanail $5 \%$ w/w and locery Medicated Nail Lacquer.

- Onychomycosis disease treatment to also use penlac medicated nail lacquers.

Future scope of nail lacquers

- Medicated nail lacquers use in nail diseases.

- Nail lacquers also use in cosmetic preparation.

- Medicated nail lacquers are use for cosmeceutical.

\section{ACKNOWLEDGEMENT}

I express my special thanks to Dr. R. Y. PATIL Principal Shankarrao Ursal College of Pharmaceutical Sciences And Research Center, Kharadi, Pune-14. I am honoured to express my profound and deep sense of gratitude towards my respectable guide Miss.T.Y.Puttewar For his creative suggestions, helpful discussion, unfailing advice constant encouragement and kind support during the project work. I would like to express my gratitude to my parents who always supported and encouraged me. Thus, I have solemnized my participation in this project with dedication to make it a success.

\section{CONCLUSION}

Fungal nail diseases are the dermatological and allergic disorders. They are harmful to nail but they can be easily prevented by using the proper treatment and use of good medicated nail lacquers. The people may get worried due to change in nail appearance but now days it is very easy to fomulate nail lacquers with good effects and less side effects the nail diseaes. People will love to use this kind of formulation.

\section{REFERENCES.}

[1] Cohen PR, Scher RK. Aging. In: Hordinsky MK, Sawaya ME, Scher RK, editors. Atlas of hair and nails. Philadelphia: Churchill Livingstone; 1999. pp. 213-25.

[2] Roberts DT, Taylor WD, Boyle J. Guidelines for treatment of onychomycosis. Br J Dermatol. 2003;148:402-10.

[3] Nathan A. Treatment of fungal nail infection. Pharm J. 2006;276:597-600.

[4] Iorizzo M, Piraccini BM, Rech G, Tosti A. Treatment of onychomycosis with oral antifungal agents. Expert Opin Drug Deliv. 2005;2:435-40.

[5] Tosti A, Piraccini BM, Lorenzi S, Iorizzo M. Treatment of non dermatophyte mold and candidaonchomycosis. DermatolClin. 2003;21:491-97.

[6] Aly, R., and T. Berger. 1996. Common superficial fungal infections in patients with AIDS. Clin. Infect. Dis. 22(Suppl. 2):S128S132.

[7] Brodell R T, Elewski B E. Superficial fungal infections: errors to avoid in diagnosis and treatment. Postgrad Med. 1997;101:279-287.

[8] Clayton, Y. M., and R. J. Hay. 1993. Epidemiology of fungal skin and nail disease: roundtable discussion held at Dermatology 2000, Vienna, 17 May 1993. Br. J. Dermatol. 130(Suppl. 4):9-11.

[9] Clinical Courier. New strategies for the effective management of superficial fungal infections. Clin Courier. 1997;16:2-3.

[10] Cohen J L, Scher R K, Pappert A S. The nail and fungus infections. In: Elewski B, editor. Cutaneous fungal infections. New York, N.Y: Igaku-Shoin Inc.; 1992. pp. 106-122.

[11] Elewski B E. Mechanisms of action of systemic antifungal agents. J Am AcadDermatol. 1993;28:S28-S34.

[12] Rippon J W. Medical mycology: the pathogenic fungi and the pathogenic actinomycetes. 3rd ed. Philadelphia, Pa: The W. B. Saunders Co.; 1988. pp. 169-275.

[13] Roseeuw D, De Doncker P. New approaches to the treatment of onychomycosis. J Am AcadDermatol. 1993;29:S45-S50.

[14] Scher R K. Diseases of the nails. In: Conn H, editor. Current therapy. Philadelphia, Pa: The W. B. Saunders Co.; 1990. pp. 736742.

[15] Drake L A, Dinehart S M, Farmer E R, Goltz R W, Graham G F, Hordinsky M K, Lewis C W, Pariser D M, Skouge J W, Webster S B, Whitaker D C, Butler B, Lowery B J.

[16] Guidelines of care for superficial mycotic infections of the skin: onychomycosis. J Am AcadDermatol. 1996;34:116-121.

[17] Del Rosso J Q, Gupta A K. Oral antifungal agents: recognition and management of adverse reactions. Today's Ther Trends. 1997; 15:75-84.

[18] Dompmartin D, Dompmartin A, Deluol A M, Grosshans E, Coulaud J P. Onychomycosis and AIDS: clinical and laboratory findings in 62 patients. Int J Dermatol. 1990;29:337-339.

[19] Nathan A. Treatment of fungal nail infection. Pharm J. 2006;276:597-600.

[20] Iorizzo M, Piraccini BM, Rech G, Tosti A. Treatment of onychomycosis with oral antifungal agents. Expert Opin Drug Deliv. $2005 ; 2: 435-40$

[21] Gupta AK, Schouten JR, Lynch LE. Ciclopirox nail lacquer 8\% for the treatment of onychomycosis: A Canadian perspective. Skin TherLett. 2005;10:1-3.

[22] Practice guidance: OTC Amorolfinenail lacquer. London: Royal Pharmaceutical Society of Britain; 2006. 
[23] British National Formulary; 59th Edition (March 2010) British Medical Association and Royal Pharmaceutical Society of Great Britain, London.3.

[24] http://www.nailsmag.com/feature.aspx?fid=762\&ft=1

[25] Manufacturer's PIL, Loceryl Nail Lacquer 5\%®; Manufacturer's PIL, Loceryl Nail Lacquer 5\%®, Galderma (UK) Ltd, electronic Medicines Compendium. Dated November 2010.

[26] Manufacturer's PIL, Curanail 5\% w/w Medicated Nail Lacquer®; Manufacturer's PIL, Curanail 5\% w/w Medicated Nail Lacquerß, Galderma (UK) Ltd, electronic Medicines Compendium. Dated November 2010.

[27] HabifDerby R, et al. (2011). Novel treatment of onychomycosis using over-the-counter mentholated ointment: A clinical case series. Journal of the AmericanBoard of Family Medicine, 24(1): 69-74.

[28] TP (2010). Fungal nail infections section of Nail diseases. In ClinicalDermatology: A Color Guide to Diagnosis and Therapy, 5th ed., pp. 956-961. Edinburgh: Mosby Elsevier.

[29] The nail in systemic diseases. Tosti A, Iorizzo M, Piraccini BM, Starace M. DermatolClin. 2006 Jul;24(3):341-7. Review.

[30] http://dermatology.about.com/cs/nailanatomy/a/nailanatomy.htm

[31] Dittmar W., Lohaus G. 1973. HOE296, A new antimycotic compound with a broad antimicrobial spectrum. ArzneimForsch./Drug Res. 23:670-674.

[32] Niewerth et. al., 1998. Antimicrobial susceptibility testing of dermatophytes: Comparison of the agar macrodilution and broth micro dilution tests. Chemotherapy. 44:31-35.

[33] Yang et. al. 1997. A new simulation model for studying in vitro topical penetration of antifungal drugs into hard keratin. J. Mycol. Med. 7:195-98

[34] http://www.nhs.uk/conditions/Fungal-nail-infection/Pages/Introduction.aspx 